\title{
Intramedullary Spinal Cord Metastases and Radiation Therapy: A Case Report
}

\author{
Daniel Ikeda \\ Thomas Jefferson University \\ James S. Harrop MD \\ Thomas Jefferson University
}

Follow this and additional works at: https://jdc.jefferson.edu/jhnj

Part of the Neurology Commons

\section{Let us know how access to this document benefits you}

\section{Recommended Citation}

Ikeda, Daniel and Harrop MD, James S. (2008) "Intramedullary Spinal Cord Metastases and Radiation Therapy: A Case Report," JHN Journal: Vol. 4 : Iss. 2 , Article 2.

DOI: https://doi.org/10.29046/JHNJ.004.2.005

Available at: https://jdc.jefferson.edu/jhnj/vol4/iss2/2

This Article is brought to you for free and open access by the Jefferson Digital Commons. The Jefferson Digital Commons is a service of Thomas Jefferson University's Center for Teaching and Learning (CTL). The Commons is a showcase for Jefferson books and journals, peer-reviewed scholarly publications, unique historical collections from the University archives, and teaching tools. The Jefferson Digital Commons allows researchers and interested readers anywhere in the world to learn about and keep up to date with Jefferson scholarship. This article has been accepted for inclusion in JHN Journal by an authorized administrator of the Jefferson Digital Commons. For more information, please contact: JeffersonDigitalCommons@jefferson.edu. 


\section{Intramedullary Spinal Cord Metastases and Radiation Therapy: A Case Report}

\author{
Daniel Ikeda, James S. Harrop MD \\ Department of Neurological Surgery, Thomas Jefferson University, Philadelphia, Pennsylvania
}

\section{Introduction}

Intramedullary spinal cord metastases (ISCM) are a clinically rare, although devastating, complication of disseminated cancer. These lesions have been reported to originate from many types of solid tumors, although primary lung carcinoma, particularly small cell, is the most common etiology. These metastases, which can occur anywhere along the spinal cord, often represent the end-stage of the disease process with limited survival outcomes.

Patients with ISCM may develop a variety of neurological deficits with treatment goals aimed at palliation. Different modalities of treatment have been found to preserve or restore ambulation and neurological function. The options for therapeutic intervention include surgical, chemotherapeutic, and radiation therapy. We describe a case of ISCM in a patient with disseminated small cell lung cancer with magnetic resonance imaging that illustrates a complete tumor response to radiation therapy

\section{Case Report}

In December of 2006, a 63 year-old male presented with extensive stage small cell lung carcinoma. Upon initial presentation, this patient had a very large, left pulmonary mass, mediastinal lymphadenopathy, multiple hepatic lesions, and several osseous lesions. Due to the extent of his disease, the patient was referred to medical oncology and treated with chemotherapy. A PET scan on July of 2007 revealed radiographic resolution of his malignancy following his chemotherapy. On October $3^{\text {rd }}$ of 2007, after presenting with dizziness, it was found he had metastasis to his cerebellar vermis. These metastases were treated with 30 Gy of whole brain radiation therapy and his vertigo significantly improved. A follow-up brain MRI showed a complete response to treatment with no residual metastases found.

In December of 2007, the patient presented with bilateral shoulder and neck pain. The pain started in his right shoulder radiating to his mid neck and then to his left shoulder. The pain had been intermittent, but intense, over the previous few weeks and progressed to right arm numbness. There was no associated muscle weakness in his upper or lower extremities bilaterally. The patient displayed some mild right hand intrinsic weakness; deep tendon reflexes were found to be slightly increased in his lower extremities versus his upper extremities. An open MRI with and without IV contrast of the cervical spine was performed. A contrast enhancing mass within the cervical spinal cord was noted and reported as an ependymoma, due to the infrequency of intraparenchymal metastasis. To get better definition of the lesion, a repeat closed high-resolution MRI of the cervical, thoracic, and lumbar spine was performed. The cervical contrast enhancing lesion was found to be three separate intramedullary multifocal with measured total length of $4.5 \mathrm{~cm}$ (Figure 1A). There were no other lesions in the spinal cord. The presence of three distinct lesions in the setting of metastatic disease was consistent with multiple intraparenchymal metastatic disease rather than a primary intramedullary neoplasm (ependymoma).

The patient's disease was in remission and $30 \mathrm{~Gy}$ of cervical spine radiation was administered. The patient reported that his symptoms of pain and numbness resolved completely with the radiation therapy.

A follow-up MRI demonstrated a complete response and no evidence of the ISCM lesion (Figure 1B).

\section{Discussion}

Although rarely reported, ISCM have been found in $0.9 \%$ to $2.1 \%$ of cancer patients by autopsy, suggesting that thousands of patients are afflicted yearly ${ }^{1}$. Primary lung carcinoma is the most common etiology and reported to occur in up to fifty percent of cases of ISCM ${ }^{2}$. In one retrospective

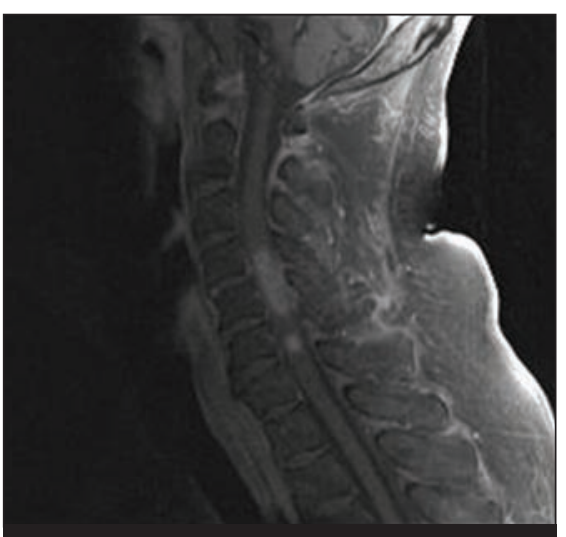

Figure 1A

Cervical MRI, prior to 30 Gy radiotherapy

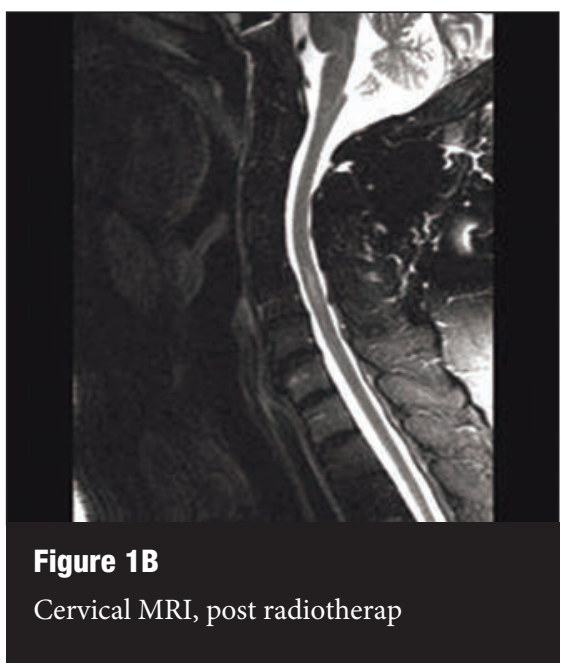

study, small cell lung cancer was the most common primary tumor in patients with ISCM, accounting for $63 \%$ of patients with primary lung cancer and $30 \%$ of all patients studied ${ }^{2}$. However, other solid tumors, including breast, kidney, colorectal, cervical, and ovarian cancers have also been reported ${ }^{3,4,5}$.

A variety of neurological disorders characterizes the presenting symptoms of ISCM clinically. Schiff and O'Neill reported sensory alteration $(42.5 \%)$, pain $(30 \%)$, and weakness $(30 \%)$ as the most common initial symptoms ${ }^{2}$. 
The symptoms of gait unsteadiness, urinary incontinence, and Brown-Sequard syndrome have also been described ${ }^{2,6}$.

Diagnosis of ISCM usually requires magnetic resonance imaging (MRI) or computerized tomography (CT), because plane films and myelography are normal in $75 \%$ and $58 \%$ of cases $^{7}$. In addition, cerebral spinal fluid (CSF) analysis is often non-diagnostic with the most common abnormal finding of elevated protein in only $20 \%$ of cases ${ }^{8}$. Computerize tomography scanning has been found to be diagnostic in few patients, which is demonstrated by increased density in the area of the ISCM lesions. However, magnetic resonance imaging (MRI) has greater sensitivity and specificity $^{7}$. MRI T2-weighted images show alterations in signal intensity based on tissue type and demonstrate accurate differentiation between normal tissue of the spinal cord and tumor ${ }^{7}$. Gadolinium is a helpful adjunct to the T2-weighted imaging as it reveals the enhancing central lesion in typical ISCM ${ }^{7}$. In a study of 30 patients, there was only one false-negative MRI study, and 23 of 25 patients receiving gadolinium demonstrated contrast enhancement of ISCM lesions on $\mathrm{MRI}^{2}$.

Treatment is generally palliative, as the median survival ranges from 3.9 to 5 months ${ }^{2,9,10}$. Schiff and O'Neill found that patients with breast cancer as their primary tumor had the greatest median survival, which still was only 13 months.
Patients with other primary cancers including lung carcinoma had a median survival of 3 months. As with our patient, surgery is often contraindicated at the time of presentation, making the less invasive modalities of chemotherapy and radiation therapy the mainstays of treatment ${ }^{2,5,11}$. Radiation therapy has been shown to improve or prevent deterioration of neurological status. In Conill et al., they reported improvement of neurological symptoms in $83 \%$ of patients with a mean duration of 17.2 days. And Schiff and O'Neill reported preservation of ambulation in $91 \%$ of patients at their latest follow-up.

\section{Conclusions}

This case illustrates a rare complication of systemic small cell lung cancer. The ISCM lesion showed a rare complete response to radiation therapy, which was evidenced by magnetic resonance imaging and outlines the importance of radiation therapy in the treatment algorithm of these patients.

\section{References}

1. Chason JL, Walker FB, Landers JW. Metastatic carcinoma in the central nervous system and dorsal root ganglia. Cancer 16:781-787, 1963

2. Schiff D, O’Neill BP. Intramedullary spinal cord metastases: clinical features and treatment outcome. Neurology 47:906912, 1996.

3. Kosmas C, Koupou M, Nikolaou M, Katselis J, et al Intramedullary spinal cord metastases in breast cancer: report of four cases and review of the literature. Journal of Neurooncology 71:67-72, 2005.
4. Amin R. Intramedullary spinal metastasis from carcinoma of the cervix. The British journal of Radiology 72:89-91, 1999.

5. Bakshi A, Biswas G, Deshmukh C, Prasad N, Nair R, Parikh PM. Successful complete regression of isolated intramedullary spinal cord metastases from epithelial ovarian carcinoma with chemotherapy and radiotherapy. Indian Journal of Cancer 43:136-138.

6. Aryan HE, Farin A, Nakaji P, Imbesi SG, Abshire BB. Intramedullary spinal cord metastasis of lung adenocarcinoma presenting as Brown-Sequard syndrome. Surgical Neurology 61:72-76, 2004.

7. Lyding JM, Tseng A, Newman A, Collins S, Shea W. Intramedullary spinal cord metastasis in Hodgkin's disease: rapid diagnosis and treatment resulting in neurologic recovery. Cancer 60:1741-1744, 1987.

8. Grem JL, Burgess J, Trump DL. Clinical features and natural history of intramedullary spinal cord metastases. Cancer 56:2305-2314, 1985.

9. Lee SS, Kim MK, Sym SJ, Kim SW, Kim WK, Kim SB, Ahn $\mathrm{JH}$. Intramedullary spinal cord metastases: a single-institution experience. Journal of Neurooncology 84:85-89, 2007.

10. Conill C, Marruecos J, Verger E, Berenguer J, Lomena F, Domingo-Domenech J, Grau JJ, Casas F. Clinical outcome in patients with intramedullary spinal cord metastases from lung cancer. Clinical \& Translational Oncology 9:172-176 2007

11. Nikolaou M, Koumpou M, Mylonakis N, Karabelis A, Pectasides D, Kosmas C. Intramedullary Spinal Cord Metastases from Atypical Small Cell Lung Cancer: A Case Report and Literature Review. Cancer Investigation 24:4649, 2006. 